stand the expert system's recommendations during practical use. This ability to give explanations accounts for much of the interest by software engineers in expert systems' techniques, and Davis gives a clear account of the techniques used in providing explanations, the concepts they are based upon and a straightforward summary of their limitations.

As a whole, the book is an impressive record of two novel pieces of work in artificial intelligence and knowledge engineering. Both monographs provide valuable information for other designers and research workers. Unfortunately, however, the book is not easy to read or easy to use. Minor subjects are dealt with in as great detail as important ones; the text is heavily punctuated with difficult notations and abbreviations; there is little crosslinkage between monographs; and there is no index. The authors are also somewhat inward looking, giving little consideration to previous thinking about knowledge or scientific discovery outside AI, or to the massive body of research on decision support which has not employed knowledge-based concepts. So while their book will be compulsive reading for the committed specialist, I fear that it will fail to convince many people who are trained in other philosophies and traditions.

Davis and Lenat have so much to say that it is a pity that they didn't say it more accessibly. To be fair their work is more briefly written up elsewhere in technical journals, but these are for an informed readership. The book was an opportunity to provide a distillation of profound ideas for a broadly based audience of scientific peers. The authors chose to write a tome. 1.7

John Fox is Head of the Biomedical Computing Unit at the Imperial Cancer Research Fund Laboratories, London.

\section{Science and Creationism}

BooKs on the response of scientists to Creationism continue to appear. For the general reader Chris McGowan has written In the Beginning . . .. A Scientist Shows Why the Creationists are Wrong, attacking the Creationists while also providing an introduction to the theory of evolution. The book is published by Macmillan of Canada and costs $\$ 18.95$.

In similar vein but more detailed is Scientists Confront Creationism, edited by Laurie R. Godfrey and published by W.W. Norton. Among the contributors are George Abell, Stephen Brush, Joel Cracraft, Stephen Jay Gould and Thomas Jukes. Price is \$19.50; the book will be published in Britain in October ( $£ 15.25$ ).

MIT Press have issued Creationism, Science, and the Law: The Arkansas Case which covers the legal and the scientific aspects of the Arkansas case of 1981. The book is edited by Marcel Chotkowski La Follette and is available in hardback $(\$ 20$, $£ 18)$ and paperback $(\$ 9.95, \mathfrak{£ 8 . 9 5 )}$.

\section{Setting the record} straight

\section{Keith Bell}

\section{L'écume de la Terre.}

By Claude J. Allègre.

Fayard, Paris: 1983. Pp.366. Fr120.

WITHIN a period of less than 20 years, the earth sciences have been turned upside down. Plate tectonics, sea-floor spreading and continental drift now provide a coherent story that links, predicts and explains a wide variety of geological phenomena, from the finding of ore deposits to the understanding of the ocean basins. Few other scientific theories have been so all-encompassing. The evidence that accumulated, partly empirical, partly theoretical and partly analytical, was so overwhelming and so convincing that a somewhat fragmented science was transformed into a smooth, fully-integrated whole. This didn't happen overnight. Ideas developed, stagnated, then were reconsidered, modified and finally accepted.

Behind all this lies a fascinating story that forms the basis of the book by C.J. Allègre, currently director of the Institute of the Physics of the Earth at the University of Paris. Partly philosophical, at times chatty, and never dull, this lucid Frenchlanguage text traces the development of ideas from Wegener's original model of continental drift through to modern plate tectonic theory. Aimed at a general audience, the book also contains a clearly written and well-illustrated summary of modern geological ideas, complete even with glossary. The gloomy vision of yet another popular tome on plate tectonics and sea-floor spreading was quickly dispelled by the author's fresh approach and his perception of the complex role that the scientific community at large plays in the world of science.

Allègre lays emphasis on an interesting, perhaps often ignored, aspect of science that the development of any science depends not only upon a scientific discovery itself but also on how it is perceived by the scientific community. We learn, rightly so, that the art of convincing is sometimes more difficult than the art of discovering. That such a book should be written by someone who, no doubt, was soaked in the classical French scientific tradition is, in itself, interesting. The duality proposed in this book of the scientific method on the one hand, and the scientific community on the other, both complementary and both interactive, seems to be a departure from traditional French scientific thought.

Although some stories are left untold, others bring out the tribulations of scientific research, the personalities of the individual researchers and the subtle ways that groups, large and small, interact with one another. There are one or two factual errors of little consequence, as well as some minor irritations, particularly the naming of contemporary researchers who were only of peripheral importance in the development of the new theories. However, this mixture of a geological Double Helix (albeit with a greater cast of characters) and a fluent account of the contemporary earth sciences is absorbing. Because of its unusual philosophical tack this book should be read by anyone interested in scientific endeavour. I hope that an English translation will soon be available.

Keith Bell is a Professor of Geology at Carleton University, Ottawa.

\section{The haemoflagellates}

\section{F.E.G. Cox}

The Biology of Trypanosoma and

Leishmania, Parasites of Man and

Domestic Animals.

By D.H. Molyneux and R.W. Ashford. Taylor \& Francis: 1983. Pp.294.

£16, \$36.

THE haemoflagellates Trypanosoma and Leishmania spp. cause Chagas' disease, sleeping sickness and leishmaniasis in man, and nagana and other diseases mainly in cattle and horses. These parasites have, over many years, attracted a vast amount of attention and the aim of the authors of The Biology of Trypanosoma and Leishmania is "to bridge the gap between what appears in textbooks and the appropriate research texts". They have tackled this formidable task remarkably successfully.

The first part of the book deals with the essential biology of the parasites and the tsetse flies, triatomid bugs and sandflies that transmit them. This section is not simply descriptive, but covers such diverse topics as ultrastructure, isoenzyme techniques in the identification of species and strains, antigenic variation, insect behaviour and insect trapping methods. The second part is concerned with African trypanosomiasis (both human and animal) and Chagas' disease, and the third with leishmaniasis. These three sections touch upon all the important facets of the infections caused by these parasites, including clinical features, treatment and control. There are two useful appendices summarizing some basic information about trypanosomes that are not of economic importance, those of small mammals, birds, reptiles and amphibians, and Leishmania enriettii, $L$. hertigi and $L$. gerbilli. Widely distributed parasites such as $T$. theileri are mentioned throughout the book.

This summary of the contents, however, does this timely and invaluable book scant justice. Throughout, the emphasis is on 